\title{
ROLE OF RESISTANCE EXERCISE IN CONTROLLING INSULIN-LIKE GROWTH FACTOR 1 (IGF-1) AND IT'S ASSOCIATION WITH METABOLIC DISEASE PREVENTION
}

\author{
Fitri Fadhilah $^{1,5}$, Abdul Hadi Hassan ${ }^{1,2}$, Hanna Goenawan ${ }^{4,5}$, Herry Herman ${ }^{3}$, \\ Aziiz Mardanarian Rosdianto ${ }^{4,5}$, Ronny Lesmana ${ }^{4,5}$ \\ ${ }^{1}$ Departemen Patobiologi, Fakultas Kedokteran, Universitas Padjajaran- RSUP Dr. Hasan Sadikin, \\ ${ }^{2}$ Departemen Patologi Anatomi, Fakultas Kedokteran, Universitas Padjajaran- RSUP Dr. Hasan Sadikin, \\ ${ }^{3}$ Departemen Ortopedik dan Traumatologi, Fakultas Kedokteran, Universitas Padjajaran- RSUP Dr. Hasan Sadikin, \\ ${ }^{4}$ Divisi Fisiologi, Fakultas Kedokteran, Universitas Padjajaran- RSUP Dr. Hasan Sadikin, \\ ${ }^{5}$ Laboratorium Fisiologi Molekular, Laboratorium Sentral, Universitas Padjadjaran.
}

\begin{abstract}
Based on data Riset Kesehatan Dasar (Riskesdas) in 2007, the people who had no or low physical activity reached $48.2 \%$. This condition contributes to increase number of metabolic disease cases such as: hypertension, heart disease, stroke and diabetes mellitus. Optimizing training approach especially aerobic type helps to counter metabolic diseases. Unfortunately, benefits of resistance training (RT) is less understood. $R T$ improves muscle strength, induce muscle hypertrophy, improvement of local muscular performance, and also help to strenghtening body balance and coordination. There is interplay between training and hormone in muscle adaptation during resistance training. Hormone plays an important role in the regeneration of muscle after resistance training. The changes of hormone level cause hypertrophy. Regeneration and muscle hypertrophy are mediated by activation, proliferation and differentiation of satellite cells. It is regulated by mitotic and myogenic activity, namely insulin-like growth factor-1 (IGF-1), which serves as a paracrine or autocrine. Better understanding of homeostasis hormone during training in skeletal muscle and its ultimate purpose to counter metabolic disease will lead us to better treatment approach for the patient.
\end{abstract}

Keywords: insulin-like growth factor-1 (IGF-1), metabolic disease, resistance training

Korespondensi: Fitri Fadhilah, Departemen Patobiologi, Fakultas Kedokteran, Universitas Padjajaran- RSUP Dr. Hasan Sadikin, J1. Eckyman No 38, Bandung, Indonesia, e-mail : ailuvito@gmail.com. 


\section{INTRODUCTION}

Prevention of metabolic diseases are closely related to lifestyle such as an unbalanced diet, lack of physical activity and smoking habits. Riset Kesehatan Dasar (Riskesdas) in 2007, reported that $48.2 \%$ of the population did not / less physical activity as recommended, the data illness among people aged $\geq 18$ years of acquired diseases hypertension $29.8 \%, 7.2 \%$ of heart disease, stroke $0.8 \%$ and $1.1 \%$ diabetes mellitus. ${ }^{1}$ The importance of resistance exercise in promoting health and preventing disease has become increasingly recognized. Resistance exercise contributes to the prevention and management of atherosclerotic coronary heart disease, hypertension, diabetes, and overweight and mild obesity. The mechanism through which resistance exercise modifies chronic disease risk may be mediated by improvements in abdominal body fat, plasma concentrations of triglyceride and high-density lipoprotein cholesterol, blood pressure, and glycemic control. $^{2}$

There is an Associations between muscular strength, a measure of the effects of resistance exercise, and disease risk, therefore, it is possible to detecting the benefits of an active and fit way of living rather than an independent benefit of resistance exercise. Muscular strength is inversely associated with all-cause mortality in men and women, independent of cardiorespiratory fitness levels. ${ }^{2}$

IGFs and their associated binding proteins play important roles in normal development and growth. IGF-1 is a key regulator of cell proliferation and an inhibitor of cell apoptosis and necrosis. In the cardiovascular system, IGF-1 is postulated to protect against endothelial dysfunction, atherosclerotic plaque development, clinical instability, and ischemic myocardial damage. Various studies have investigated the effect of serum IGF-1 concentration on development of cardiovascular diseases (CVD) and mortality. In two previous studies on the association of IGF1 with the metabolic syndrome in older populations, U-shaped relationships have been reported. Others report low IGF-1 values to be related to a greater metabolic burden. Lownormal IGF-1 level shave been associated with development of ischemic heart disease and stroke. $^{3}$

\section{RESISTANCE EXERCISE}

Extensive research reveals that resistance training is an effective method to improve muscle strength, endurance, power, and is also effective for improving the health status of most individuals, not just a competitive athlete. ${ }^{4}$ Resistance exercise is any physical activity that causes the muscles to work against force or additional load. Each muscle group can benefit from resistance training. ${ }^{4}$ Resistance exercise is recommended by some health organizations because it has potential benefits to health and fitness associated with the performance of the body. ${ }^{5,6}$ Resistance training can improve muscle strength, speed, hypertrophy, local muscular endurance, performance, balance and coordination. Thus, participation in the resistance exercise can produce a number of favorable responses that contribute to health and can reduce or even prevent some functional decline associated with aging.

\section{ROLE OF RESISTANCE EXERCISE IN THE PREVENTION OF METABOLIC DISEASES}

Until now, there has been enough evidence to support the role of resistance exercise in health promotion or disease prevention. ${ }^{6}$ The important role of resistance exercise in health promotion is that resistance training, compared with aerobic training, have the ability to reduce fat mass (especially abdominal and visceral fat). ${ }^{6,7}$ While simultaneously increasing body mass for someone slender, this can occur even in the absence of changes in food intake, total kilo calories, carbohydrates, protein and fat. ${ }^{7}$

Resistance training can increase bone mineral density as much as $1-3 \%{ }^{8}$ Resistance exercise has also been shown to improve heart health by lowering blood pressure at rest, ${ }^{6}$ increase or decrease lipid lipoprotein profile triglycerides, increase high-density lipoprotein cholesterol $^{9}$ and reduces the need for 
cardiovascular physical activity. ${ }^{10}$

Resistance training has the unique ability to improve the properties of muscle metabolism that may help in the management and / or prevention of type 2 diabetes by reducing visceral fat, reduce the level of HbA1c, increasing the density of the glucose transporter type 4 and increase insulin sensitivity. ${ }^{7,11}$ Resistance training its very important to reduce the risk of falls, particularly in the elderly ${ }^{12}$ and also to reverse certain aging factors in skeletal muscle (sarcopenia) and reduce the risk and severity of musculoskeletal injuries. $^{13}$

In the case of musculoskeletal health promotion, resistance training has been shown to be effective for reducing pain and reduce discomfort, inflammation, muscle weakness and fatigue associated with arthritis and fibromyalgia. $^{7}$

\section{ROLE OF RESISTANCE EXCERCISE IN HORMONAL REGULATION}

Resistance exercise has been shown to elicit a significant acute hormonalresponse. It appears that this acute response is more critical to tissue growth andremodelling than chronic changes in resting hormonal concentrations, as many studies have not shown a significant change during resistance training despite increases in muscle strength and hypertrophy. ${ }^{14}$

Anabolic hormones such as testosterone and the superfamily of growth hormones $(\mathrm{GH})$ have been shown to be elevated during 15-30 minutes of post-resistance exercise providing an adequate stimulus is present. Protocols high in volume, moderate to high in intensity, using short rest intervals and stressing a large muscle mass, tend to produce the greatest acute hormonal elevations (e.g. testosterone, $\mathrm{GH}$ and the catabolic hormone cortisol) compared with low-volume, high-intensity protocols using long rest intervals. Acute elevations in catecholamines are critical to optimal force production and energy liberation during resistance exercise. More recent research has shown the importance of acute hormonal elevations and mechanical stimuli for subsequent up- and down-regulation of cytoplasmic steroid receptors needed to mediate the hormonal effects. Other factors such as nutrition, overtraining, detraining and circadian patterns of hormone secretion are critical to examining the hormonal responses and adaptations to resistance training. ${ }^{14}$

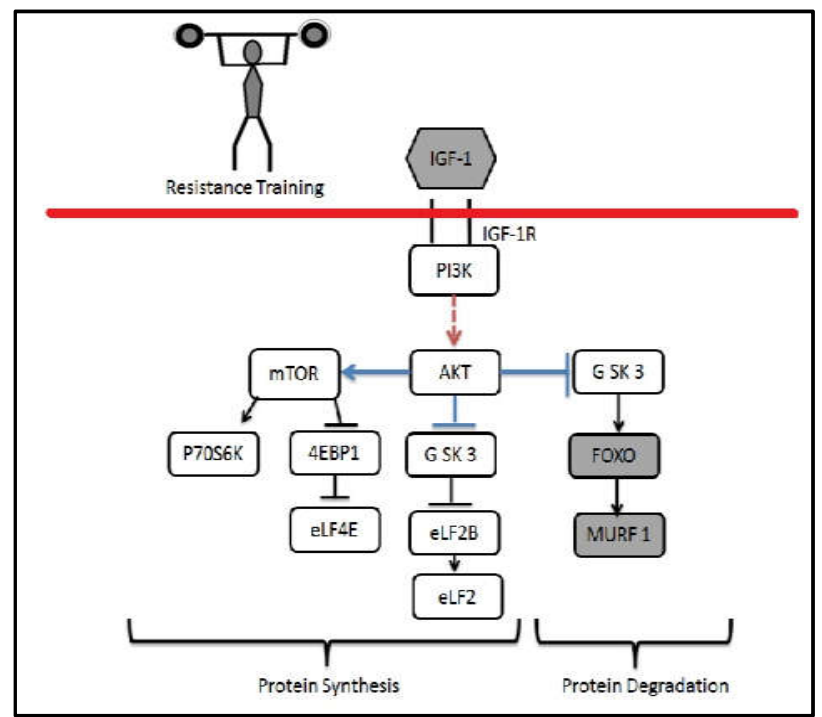

Fig. 1 Signalling pathways regulated by exercise and/or IGF-I. Resistance exercise has been shown to activate Akt and induces IGF-I synthesis in muscle. $\mathrm{PI} 3 \mathrm{~K} / \mathrm{Akt}$ is of particular importance as it increases protein synthesis via mTOR activation and inhibits protein degradation via the inactivation of FOXO transcription factors with resistance training. AMPKactivation leads to PGC- $1 \alpha$ activation and induces mitochondrial biogenesis with endurance training. mTOR $=$ mammalian target of rapamycin; $\mathrm{PI} 3 \mathrm{~K}=$ phosphatidylinositol 3-kinase; eIF2 = eukaryotic initiation factors 2 ; eIF = eukaryotic initiation factors, including $4 \mathrm{E}$ and $2 \mathrm{~B}$; $4 \mathrm{EBP} 1=4 \mathrm{E}$ binding protein 1 ; ATP (adenosine triphosphate) AMPK = AMP (adenosine monophosphate)-activated protein kinase; MuRF1=muscle RING finger 1; FOXO = Forkhead box; PGC- $1 \alpha=$ Peroxisome proliferator-activated receptor- $\gamma$ coactivator $1 \alpha$.

\section{ROLE OF HORMONE INSULIN-LIKE GROWTH FACTOR-1 (IGF-1) IN EXERCISE RESISTANCE}

Hormones play an important role in the regeneration of muscle after resistance exercise and changes in hormone levels has the effect of hypertrophy. Muscle hypertrophy occurs due to an increase in acute exercise on anabolic androgen hormones that can increase the amount of receptor interaction thus causing intermediate changes in muscle size and neuromuscular function. This occurs because the process of adaptation to the mechanisms of 
production in the endocrine system. ${ }^{15}$

Skeletal muscle can not only increase the mass as an adaptation to a given mechanical load but also regenerate after damage through intrinsic regulation of gene transcription. Both cellular processes, the regeneration and muscle hypertrophy mediated by activation, proliferation and differentiation of satellite cells are regulated by mitotic activity and myogenic locally produced, namely insulin-like growth factor-1 (IGF-1), which serves as a paracrine or autocrine. ${ }^{15,16}$

Insulin-like growth factor-1 plays a major role in tissue remodeling through upregulation by the mechanical signal (ie the increase in gene expression resulting from the stretch and strain on the muscle cytoskeleton that leads to the level of protein synthesis is greater). Acute elevation in catecholamines is essential for optimum power production and the release of energy during resistance exercises. Research has shown the importance of improving the acute hormonal and mechanical stimuli to increase and decrease regulation of cytoplasmic steroid receptors. Other factors such as nutrition, overtraining, detraining and patterns of hormone secretion is very important to check the hormonal responses and adaptations to resistance training. ${ }^{5}$

Insulin-like growth factor (IGF) is the main intermediary of the effects of growth hormone (Growth Hormone). Growth hormone is made in the anterior pituitary gland, is released into the bloodstream, then stimulates the liver to produce insulin-like growth factor 1. Insulin-like growth factor -1 (IGF-1) can stimulate the the body's systems growth, and stimulate growth that affect almost every cell in the body like skeletal muscle,cartilage, bone, liver, kidneys,nerves, skin, hematopoietic cells, and lungs. Insulin-like growth factor -1 can also regulate cell growth and development, especially in nerve cells, as well as the synthesis of DNA cells. ${ }^{17}$

Insulin-like growth factor system is an important determinant skeletal muscle growth.

The main mechanism action of insulin-like growth factor to stimulate muscle hypertrophy is the proliferation and differentiation of muscle precursor cells, known as myoblasts. ${ }^{17}$

\section{CLINICAL STUDIES}

The role of resistance exercise in increasing levels of IGF-1 remains to be studied further. Abe et al. ${ }^{18}$ Has been conducting research withinvestigated the effects of twice daily sessions of low-intensity resistance training (LIT, 20\% of 1-RM) with restriction of muscular venous blood flow (namely "LITKaatsu" training) for two weeks on skeletal muscle size and circulating insulin-like growth factor-1 (IGF-1). Nine young menperformed LIT-Kaatsu. Training was conducted two times / day, six days / week for 2 weeks using 3 sets of two dynamic exercises (squat and leg curl). Serum IGF-1 concentration was measured at baseline, mid-point of the training and posttesting. In the LIT-Kaatsu group, serum IGF-1 increased progressively and reached significance $(p<0.05)$ after 2 weeks of training.

Another study by Marx et al. ${ }^{19}$ Investigation to determine the long-term training adaptations associated with lowvolume circuit-type versus periodized highvolumeresistance training programs in women. 34 healthy, untrained women were randomly placed into one of the following groups: low-volume, single-set circuit (SSC); periodized high-volume multiple-set (MS); or nonexercising control (CON) group. The SSC group performed one set of 8-12 repetitions to muscular failure $3 \mathrm{~d} \cdot \mathrm{wk}-1$. The MS group performed two to four sets of 3-15 repetitions with periodized volume and intensity $4 \mathrm{~d} \cdot \mathrm{wk}-1$. Resting hormonal concentrations were determined pretraining (T1), after $12 \mathrm{wk}$ (T2), and after 24 wk of training (T3). Serum IGF-1 increased significantly in SSC at T3 compared with T1 and in MS at T2 and T3 compared with $\mathrm{T} 1$.

It is concluded that serum IGF-1 will increased significantly after resistance excercise. Further studies are required to determine the role of resistance training to increased concentration of IGF-1 level and its role in the prevention of metabolic diseases. 


\section{REFERENCES}

1. RI BP dan PK kementerian K. Riset Kesehatan Dasar [RISKESDAS]. 2007;

2. Blair SN. Association of Muscular Strength with Incidence of Metabolic Syndrome in Men. Med Sci Sport Exerc. 2005;(15):1849-56.

3. Bunderen CC Van, Oosterwerff MM, Schoor NM Van, Deeg DJH, Lips P. Serum IGF1, metabolic syndrome, and incident cardiovascular disease in older people : a population-based study. Eur $J$ Endocrinol. 2013;168(3):393-401.

4. Cornelissen VA, Fagard RH, Coeckelberghs E, Vanhees L. Impact of resistance training on blood pressure and other cardiovascular risk factors: A metaanalysis of randomized, controlled trials. Hypertension. 2011;58(5):950-8.

5. Hurley BF, Hanson ED, Sheaff AK. Strength training as a countermeasure to aging muscle and chronic disease. Sports Med. 2011:289-306.

6. Shaw BS, Shaw I, Mamen A. Contrasting effects in anthropometric measures of total fatness and abdominal fat mass following endurance and concurrent endurance and resistance training. $J$ Sports Med Phys Fitness. 2010;50(2):207-13.

7. Westcott WL. Resistance training is medicine: effects of strength training on health. Curr Sports Med Rep. 2012;11(4):209-16.

8. Westcott WL, Winett RA, Annesi JJ, Wojcik JR, Anderson ES, Madden PJ. Prescribing physical activity: applying the ACSM protocols for exercise type, intensity, and duration across 3 training frequencies. Phys Sports Med. 2009;37(2):51-8.

9. Williams $\mathrm{AD}$, Almond $\mathrm{J}$, Ahuja KDK, Beard DC, Robertson IK, Ball MJ. Cardiovascular and metabolic effects of community based resistance training in an older population. $J$ Sci Med Sport. 2011;14(4):331-7.

10. Deschenes MR, Kraemer WJ. Performance and physiologic adaptations to resistance training. Am J Phys Med Rehabil. 2002;81(11 Suppl):S3-16.
11. Bweir S, Al-Jarrah M, Almalty A-M, Maayah M, Smirnova I V, Novikova L, et al. Resistance exercise training lowers HbAlc more than aerobic training in adults with type 2 diabetes. Diabetol Metab Syndr. 2009;1:27.

12. Phillips SM. Resistance exercise: good for more than just Grandma and Grandpa's muscles. Appl Physiol Nutr Metab. 2007;32(6):1198-205.

13. Rhodes Serra, Francisco Saavedra, Belmiro Freitas de Salles, Marcelo Ricardo Dias, Pablo B. Costa, Hugo Alves RS. The Effects of Resistance Training Frequency on Strength. $J$ Excercise Physiol. 2015;18(1):37-45.

14. Kraemer WJ, Ratamess N a. Hormonal responses and adaptations to resistance exercise and training. Sports Med. 2005;35(4):339-61.

15. Fry AC. The role of resistance exercise intensity on muscle fibre adaptations. Sports Med. 2004:663-79.

16. Hameed M, Orrell RW, Cobbold M, Goldspink G, Harridge SDR. Expression of IGF-I splice variants in young and old human skeletal muscle after high resistance exercise. $J$ Physiol. 2003;547(Pt 1):247-54.

17. Philippou A, Halapas A, Maridaki M, Koutsilieris M. Type I insulin-like growth factor receptor signaling in skeletal muscle regeneration and hypertrophy. $J$ of Musculoskelet Neuronal Interact. 2007:208-18.

18. Abe T, Yasuda T, Midorikawa T, Sato Y, Kearns CF, Inoue $\mathrm{K}$, et al. Skeletal muscle size and circulating IGF-1 are increased after two weeks of twice daily. Int $J$ KAATSU resistance training. 2005;1:6-12.

19. Marx JO, Ratamess NA, Nindl BC, Gotshalk LA, Volek JS, Mazzetti SA, et al. Low-volume circuit versus highvolume periodized resistance training in women. Med Sci Sports Exerc. 2001:33(4):635-643. 